\title{
Architectural Design, Interior Decoration, and 3-D Plumbing en route to Multifunctional Nanoarchitectures
}

JEFFREY W. LONG*AND DEBRA R. ROLISON*

Surface Chemistry Branch, Code 6170, Naval Research Laboratory, Washington, D.C. 20375, USA

SUPPLEMENTAL INFORMATION

Video S.1.

Jeffrey Long received a B.S. in Chemistry with Honors from Wake Forest University in 1992. Working with Professor Royce Murray, he earned a Ph.D. in Chemistry from the University of North Carolina at Chapel Hill in 1997. His research focuses on nanostructured materials, particularly hybrid nanoarchitectures for applications in sensing, separations, and electrochemical energy storage and conversion. E-mail: jeffrey.long@nrl.navy.mil.

Debra Rolison received a B.S. in Chemistry from Florida Atlantic University in 1975 and a Ph.D. in Chemistry from the University of North Carolina at Chapel Hill in 1980 under the direction of Royce W. Murray. She joined the Naval Research Laboratory as a research chemist in 1980 and currently heads the Advanced Electrochemical Materials section; she is also an Adjunct Professor of Chemistry at the University of Utah. Her research at the $\mathrm{NRL}$ focuses on multifunctional nanoarchitectures with special emphasis on catalysis, energy storage and conversion, biomolecular composites, porous magnets, and sensors. E-mail: rolison@nrl.navy.mil. 